\title{
Влияние ионно-лучевой обработки в процессе ВЧ магнетронного распыления на свойства пленок ZnO
}

\author{
() П.Н. Крылов, А.С. Алалыкин, Е.А. Дурман, Р.М. Закирова, И.В. Федотова \\ Удмуртский государственный университет, \\ 426034 Ижевск, Россия \\ E-mail: ft@@udsu.ru
}

Поступила в Редакцию 21 марта 2019 г.

В окончательной редакции 7 июня 2019 г.

Принята к публикации 17 июня 2019 г.

Рассмотрено влияние ионно-лучевой обработки, чередующейся с процессом магнетронного напыления, на свойства тонких пленок оксида цинка. Ионно-лучевая обработка вызывает уменышение скорости роста, размеров областей когерентного рассеяния и удельного сопротивления. Стехиометрический индекс, ширина запрещенной зоны и показатель преломления увеличиваются. Прозрачность пленок в области слабого поглощения не меняется.

Ключевые слова: ионно-лучевая обработка, оксид цинка, магнетронное распыление.

DOI: 10.21883/FTP.2019.11.48444.9110

\section{1. Введение}

Оксид цинка - прямозонный полупроводник с шириной запрещенной зоны 3.37 эВ при $300 \mathrm{~K}$. ZnO характеризуется высокой подвижностью электронов, хорошей прозрачностью и люминесценцией при температуре $300 \mathrm{~K}$ [1]. Пленки $\mathrm{ZnO}$ имеют хорошую химическую инертность и устойчивость к влиянию атмосферы [2]. Оксид цинка может применяться в качестве функциональных слоев в устройствах на поверхностных акустических волнах, источниках и детекторах ультрафиолетового и инфракрасного излучения, оптических затворах, элементах нелинейной оптики, для создания хорошо проводящих областей и тонких переходных слоев солнечных батарей и устройств вывода информации [3]. Способность пленок $\mathrm{ZnO}$ в нагретом состоянии адсорбировать газы, изменяя проводимость, позволяет использовать их для создания активных элементов газовых датчиков [4]. Повышенное внимание к оксиду цинка обусловлено также хорошими пьезоэлектрическими и люминесцентными свойствами [5]. Большое число работ, посвященных оксиду цинка, показывает актуальность исследования влияния условий изготовления пленок на их свойства. Отдельного внимания заслуживают процессы, при которых происходят изменения свойств пленок во время синтеза [6]. Одним из таких методов получения пленок $\mathrm{ZnO}$ является магнетронное напыление с ионным ассистированием [6,7].

Методы ионного ассистирования дают возможность контролировать состав и энергию бомбардирующих частиц, активно управлять процессом формирования пленок и тем самым обеспечивать условия получения пленок с заданными структурно-фазовыми свойствами. При ионном ассистировании процесс осаждения происходит с одновременной ионной обработкой.

При разнесении во времени и пространстве магнетронного напыления и ионно-лучевой обработки значительно расширяются возможности модификации тонких пленок [8]. Чередующиеся процессы магнетронного напыления и ионно-лучевой обработки, при которой длина пробега ионов будет сравнима с толщиной напыленного за один проход слоя, позволяет наносить пленки микронных толщин, равномерно модифицированные по глубине. Применительно к пленкам Indium ten oxide (ITO), полученным данным методом, показана возможность изменять преимущественную ориентацию кристаллитов, уменьшать размеры областей когерентного рассеяния, увеличивать окно оптической прозрачности и концентрацию основных носителей заряда [9-11], изменять компонентный состав [12] и внутренние напряжения [13], а также значительно увеличить коэффициент отражения в ближнем ИК диапазоне [14].

В данной работе пленки оксида цинка получены с применением метода модификации свойств ионно-лучевой обработкой в процессе реактивного ВЧ магнетронного распыления; исследовано влияние ионно-лучевой обработки, чередующейся с процессом ВЧ магнетронного распыления, на свойства и структуру пленок $\mathrm{ZnO}$.

\section{2. Методика эксперимента}

Пленки оксида цинка получали ВЧ магнетронным распылением мишени ZnO на модернизированной установке УРМ [8], в смотровые окна которой были помещены планарный магнетрон и ионный источник Радикал M-100. Перед осаждением проводили ионную очистку подложек в рабочей смеси. Режимы очистки: давление $10^{-1}$ Па, напряжение ионного источника $-1.5 \mathrm{\kappa B}$, ток разряда - $100 \mathrm{мA}$. Напыление пленок проводили в среде $\mathrm{Ar}$ и $\mathrm{N}_{2}(91: 9 \%)$ при мощности ВЧ разряда 300 Вт, давление в камере в процессе нанесения составляло $3.5 \cdot 10^{-1}$ Па. Напуск рабочей смеси производили через ионный источник, что позволило обеспечить одновременную работу ионного источника и магнетрона. 

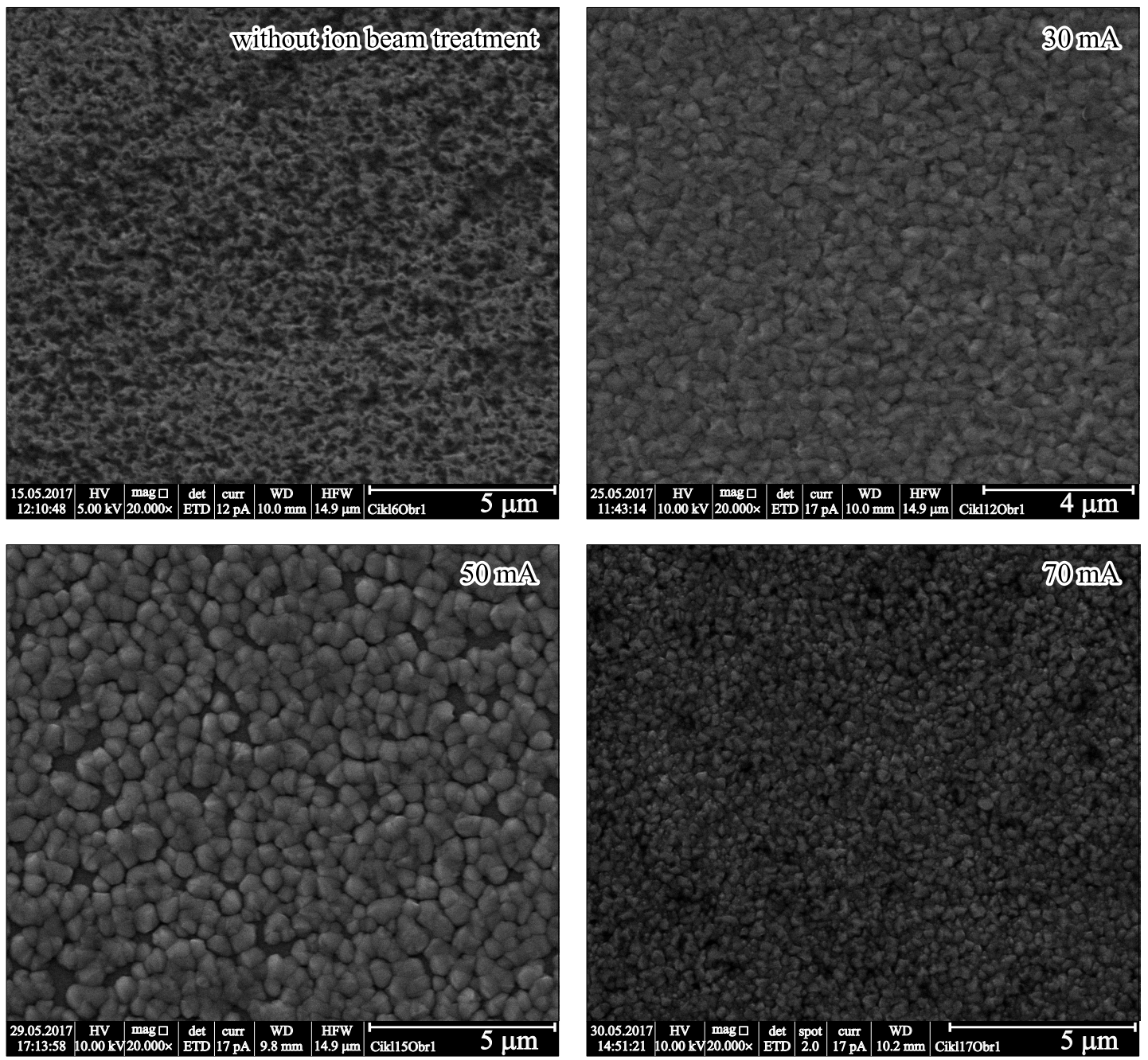

Рис. 1. Морфология поверхности пленок $\mathrm{ZnO}$, увеличение $\times 20000$.

Ионный источник использовался для проведения дополнительной обработки ионами газовой смеси аргона и азота поверхности растущих пленок. Во время процесса напыления пленок подложки поочередно проходили области магнетрона и ионного источника. Ток разряда ионного источника составлял $30,40,50,60$ и $70 \mathrm{MA.}$ Пленки наносили на стеклянные подложки, температура которых поддерживалась $300^{\circ} \mathrm{C}$.

Морфологию и элементный состав полученных пленок $\mathrm{ZnO}$ изучали на сканирующем электронном микроскопе FEI Inspect S50 с энерго-дисперсионной приставкой для элементного анализа EDAX. Расчет размеров зерен проводили с помощью программы ImageJ (погрешность 10\%).

Кристаллическую структуру тонких пленок оксида цинка исследовали на автоматизированном рентгеновском дифрактометре ДРОН-3 [15] в $\mathrm{Fe} K_{\alpha}$-излучении в диапазоне брэгговских углов $2 \theta$ от 20 до $105^{\circ}$ с шагом $\Delta 2 \theta=0.1^{\circ}$ и временем набора импульсов в точке 30 с. Размеры средних областей когерентного рассеяния (ОКР) оценивали по формуле Селякова-Шеррера [16].
Параметр решетки с оксида цинка определяли по стандартной методике [16].

Толщину пленок измеряли с помощью интерферометра МИИ-4. Для уточнения толщины и определения показателя преломления пленок $\mathrm{ZnO}$ использовали конвертный метод обработки осциллирующих спектров пропускания и отражения [17], которые были сняты с помощью спектрофотометра СФ-56 в интервале длин волн 300-1100 нм. Ширину запрещенной зоны находили по краю собственного поглощения $[5,18]$. Величину электросопротивления определяли четырехзондовым методом.

\section{3. Результаты}

Изображения поверхности пленок $\mathrm{ZnO}$ представлены на рис. 1.

Без ионно-лучевой обработки поверхность пленки оксида цинка „рыхлая“, мелкозернистая (средний размер зерен составил $\sim 210 \mathrm{Hм})$. Ионно-лучевая обработка, чередующаяся с магнетронным напылением, приводит 


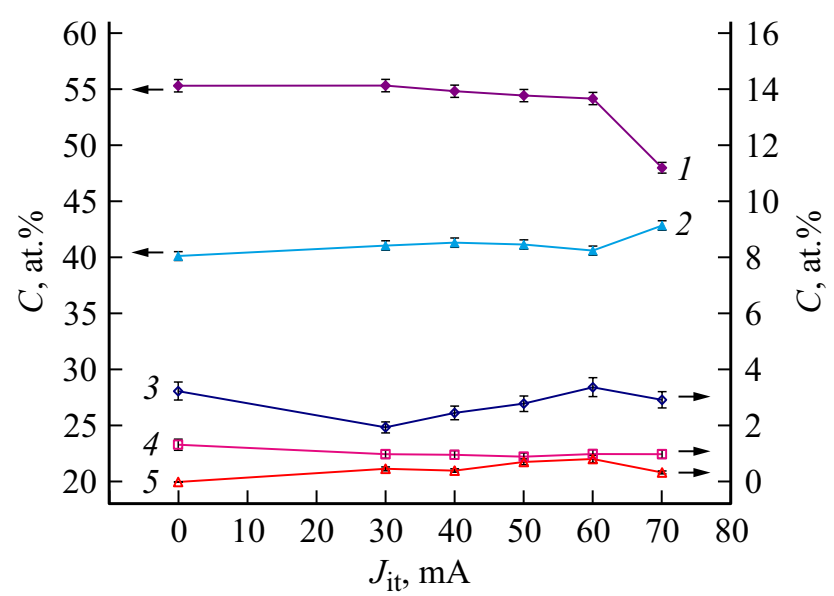

Рис. 2. Изменение содержания элементного состава в зависимости от тока ионной обработки: $1-\mathrm{Zn}, 2-\mathrm{O}, 3-\mathrm{N}$, $4-\mathrm{Ne}, 5-\mathrm{Ar}$.

к увеличению размеров зерен. С ростом тока ионного источника от 30 до 50 мА размеры зерен увеличиваются от 450 до $630 \mathrm{Hм}$, при дальнейшем росте тока ионного источника (60 и $70 \mathrm{MA})$ размер зерен уменьшается до $\sim 320$ нм.

Исследование элементного состава показывает, что пленки оксида цинка содержат $\mathrm{Zn}, \mathrm{O}$, в незначительных количествах $\mathrm{N}, \mathrm{Ne}$, а после введения ионно-лучевой обработки в пленках появляется Ar. Концентрация элементов меняется в зависимости от режима получения пленок. Пленки $\mathrm{ZnO}$, полученные без ионно-лучевой обработки, содержат 55 ат\% Zn и 40 ат\% О. Стехиометрический индекс без учета примесных атомов соответствует 0.73. Использование ионно-лучевой обработки приводит к незначительному увеличению концентрации атомов кислорода, изменению концентрации атомов азота от 1.95 до $3.38 \mathrm{aT} \%$, неона — от 0.9 до $1.33 \mathrm{aT} \%$, аргона - от 0 до 0.84 ат\%, уменьшению концентрации атомов цинка (рис. 2). С введением ионно-лучевой обработки стехиометрический индекс увеличивается до 0.89 . Следует отметить, что неон попал в пленку из баллона с аргоном, в котором он присутствовал в незначительном количестве.

Рентгенодифракционные исследования показывают, что пленки оксида цинка, полученные без ионно-лучевой обработки, являются поликристаллическими (рис. 3), с преимущественной ориентацией некоторой доли кристаллитов вдоль направления, совпадающего с осью с, перпендикулярной поверхности пленки. Размеры ОКР, оцененные по дифракционному отражению (002), составляют $12 \pm 2$ нм.

Ионно-лучевая обработка в процессе осаждения приводит к увеличению ширины дифракционных отражений и к увеличению доли кристаллитов оксида цинка с преимущественной ориентацией оси $c$ перпендикулярно поверхности пленок. Наиболее ориентированными являются пленки оксида цинка, полученные при токе ионного источника 50 мА. Размеры ОКР оксида цинка (для отражения (002)) при всех режимах ионной обработки уменьшаются до $7 \pm 2$ нм.

Введение ионно-лучевой обработки и увеличение тока ионного источника сдвигает дифракционные отражения в сторону меньших углов 20. Параметр решетки с оксида цинка больше табличного значения параметра решетки с оксида цинка ( $c=5.205 \AA)$.

Пропускание полученных пленок $\mathrm{ZnO}$ в диапазоне $500-1100$ нм составляет $75-85 \%$ (рис. 4). Ионная обработка в процессе осаждения не влияет на прозрачность

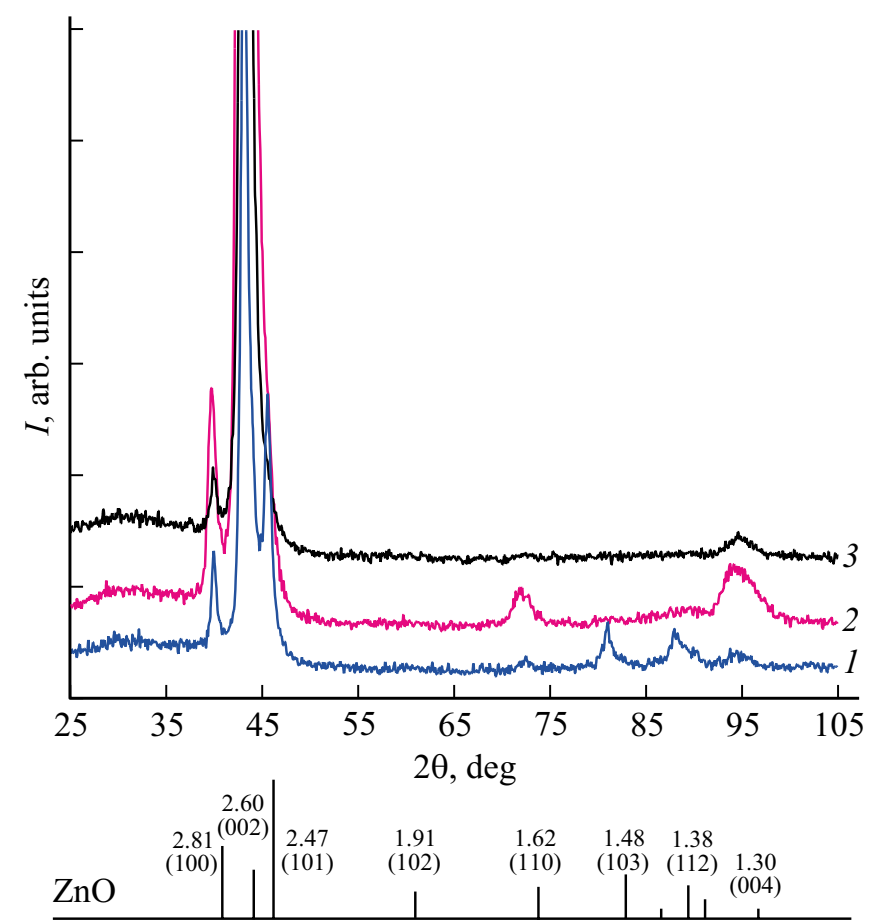

card N 36-1451

Рис. 3. Дифрактограммы пленок $\mathrm{ZnO}$, полученных при: 1 - без ионной обработки, $2-30$ мА, $3-70$ мА и штрихдиаграмма $\mathrm{ZnO}$.

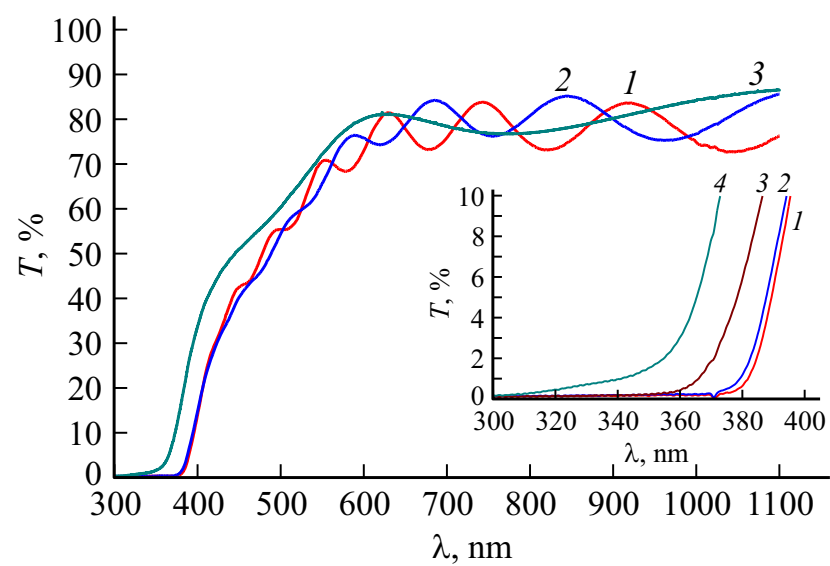

Pис. 4. Спектры пропускания пленок $\mathrm{ZnO}: 1$ - без ионной обработки, 2 - ток $40 \mathrm{MA}, 3$ - ток 70 мА. На вставке : изменение края поглощения пленок $\mathrm{ZnO}: 1$ - без ионной обработки, 2 - ток 40 мА, 3 - ток 60 мА, 4 - ток 70 мА. 
получаемых пленок оксида цинка в области слабого поглощения. Край полосы поглощения для всех пленок находится в области 360-390нм. С увеличением тока ионного источника край поглощения пленок оксида цинка смещается в коротковолновую область (см. вставку на рис. 4). Ширина запрещенной зоны изменяется от 3.13 эВ (без ионно-лучевой обработки) до 3.22 эВ (ток ионного источника $70 \mathrm{MA})$. Показатель преломления пленок $\mathrm{ZnO}$, полученных без ионно-лучевой обработки, $n=1.89$, ионно-лучевая обработка приводит к росту показатель преломления до $n=1.98$ (ток ионного источника $70 \mathrm{MA})$.

Для характеристики пленок часто используют термин коэффициент упаковки (коэффициент заполнения) или, иначе, относительная плотность. Относительная плотность $\rho$ определяется отношением плотности пленки $\rho_{f}$ к плотности массивного образца $\rho_{m}$, при этом относительная плотность и показатель преломления связаны соотношением [19]

$$
\rho=\frac{\rho_{f}}{\rho_{m}}=\frac{n_{f}^{2}-1}{n_{f}^{2}+2} \frac{n_{m}^{2}+2}{n_{m}^{2}-1},
$$

где $n_{f}$ и $n_{m}=2.01$ - показатели преломления пленки и массивного $\mathrm{ZnO}$.

Относительная плотность полученных пленок оксида цинка увеличивается от 0.91 (без ионно-лучевой обработки) до 0.98 (ток ионного источника $70 \mathrm{MA}$ ), что свидетельствует об уплотнении пленок оксида цинка при использовании ионно-лучевой обработки в процессе нанесения. Зависимость изменения показателя преломления от тока ионной обработки (рис. 5) коррелирует с зависимостью суммарной концентрации примесей (N, Ne и $\mathrm{Ar}$ ).

Ионно-лучевая обработка, чередующаяся с магнетронным распылением, оказывает влияние на скорость роста (толщину) растущей пленки. С увеличением тока ионной обработки скорость роста (толщина) пленок уменьшается (рис. 6).

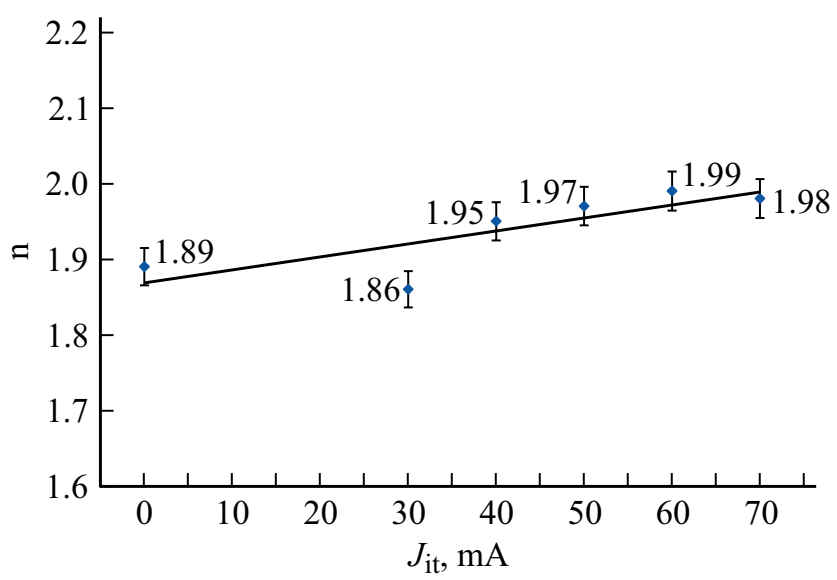

Рис. 5. Зависимость показателя преломления от тока ионной обработки.

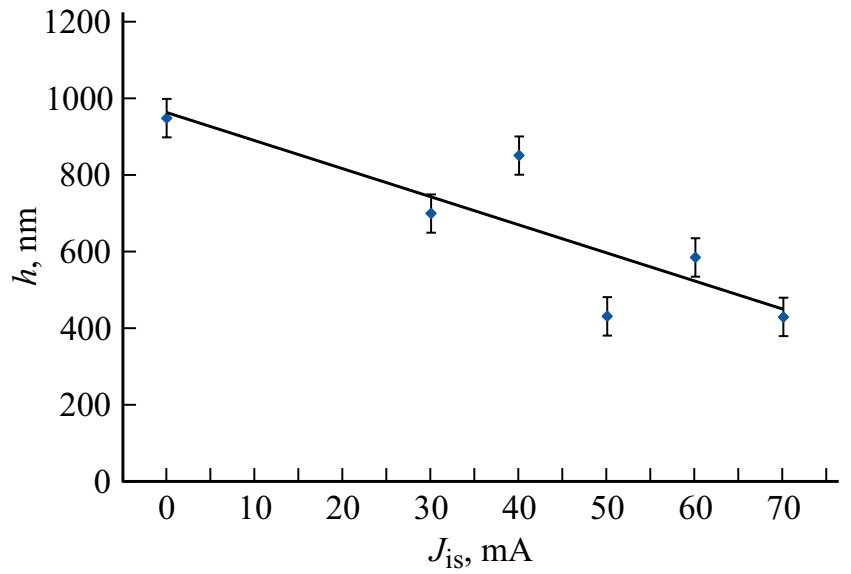

Рис. 6. Влияние тока ионного источника на толщину пленок.

Удельное сопротивление пленок оксида цинка уменьшается от $52.2 \mathrm{OM} \cdot \mathrm{cm}$ (без ионной обработки) до 0.3 Ом · см (ток ионного источника $70 \mathrm{MA}$ ).

Таким образом, сопутствующая ионно-лучевая обработка изменяет размер зерен оксида цинка, степень преимущественной ориентации кристаллитов и размеры ОКР, ширину запрещенной зоны, показатель преломления и коэффициент упаковки, увеличивает стехиометрический индекс, приводит к захвату атомов аргона, азота и неона, к сдвигу дифракционных отражений и сдвигу края поглощения, уменьшает скорость роста и удельное сопротивление пленок.

\section{4. Обсуждение полученных результатов}

Все изменения свойств растущих пленок оксида цинка при введении ионно-лучевой обработки в процесс их нанесения, очевидно, связаны с изменением дефектного состояния.

Согласно [20], кристаллическая фаза образцов $\mathrm{ZnO}$ склонна к двойникованию, проявляющемуся в различной степени для разных условий процесса формирования и положения анализируемого участка пленки относительно мишени. При низкой вероятности термосорбции неокисленного цинка с растущей поверхности он, не образуя самостоятельной металлической фазы, препятствует разрастанию кристаллитов $\mathrm{ZnO}$ и создает в них большое количество межузельных дефектов [21]. Сдвиг интерференционных отражений в сторону меньших углов $2 \theta$ относительно табличных данных может свидетельствовать о больших сжимающих механических напряжениях в пленках и наличии в них различного рода дефектов [21]. Однако в [20] отмечено, что подобное изменение параметров решетки пленок $\mathrm{ZnO}$ объясняется созданием сильно неравновесной концентрации межузельных атомов Zn как одного из основных типов собственных дефектов в $\mathrm{ZnO}$. Кроме точечных дефектов (межузельные атомы цинка, кислородные ва- 
кансии), увеличивают параметры решетки кристаллического $\mathrm{ZnO}$ также и протяженные дефекты (комплексы дислокаций) [22]. При нанесении пленок при низкой температуре внедренные в междоузлия и выбитые из них атомы имеют низкую подвижность в приповерхностном слое осаждаемой пленки [23]. Эти дефекты являются причиной высоких сжимающих напряжений. По мере роста пленки эти напряжения могут накапливаться и в дальнейшем релаксировать с образованием дислокаций.

Литературные данные об энергии образования дефектов в структуре пленок оксида цинка весьма противоречивы. Согласно [24], точечные дефекты в оксиде цинка могут присутствовать в большом количестве благодаря их низкой энергии образования. Наиболее распространенными собственными дефектами оксида цинка являются: вакансии цинка $\left(V_{\mathrm{Zn}}\right)$, вакансии кислорода $\left(V_{\mathrm{O}}\right)$, межузельный цинк $\left(\mathrm{Zn}_{i}\right)$, межузельный кислород $\left(\mathrm{O}_{i}\right)$, антисайт - атом цинка на месте атома кислорода $\left(\mathrm{Zn}_{\mathrm{O}}\right)$, антисайт - атом кислорода на месте атома цинка $\left(\mathrm{O}_{\mathrm{Zn}}\right)$. Также в оксиде цинка возможны комплексные дефекты, включающие в себя $\mathrm{Zn}_{i}, \mathrm{O}_{\mathrm{Zn}}, V_{\mathrm{O}}$ [25]. Надежных сведений по экспериментальным методам определения природы дефектов в оксиде цинка к настоящему времени не обнаружено. Имеются работы по исследованиям дефектов расчетными методами.

Межузельный цинк и цинк в антиположении имеют высокие энергии образования [26]. Атом цинка, расположенный в узле атома кислорода, значительно снижает энергию системы за счет более низкой симметрии, однако энергия образования $\mathrm{ZnO}$ сравнима с энергией образования $V_{\mathrm{O}}$ в нестехиометрических условиях, с избытком Zn [27]. Вследствие того, что межузельные атомы цинка $\mathrm{Zn}_{i}$ имеют высокую энергию образования, они присутствуют в очень низких концентрациях [28]. В структуре вюрцита межузельный цинк $\left(\mathrm{Zn}_{i}\right)$ может находиться в тетраэдрическом или октаэдрическом расположении, октаэдрическое расположение энергетически более выгодно [27,29]. Согласно [30], межузельные атомы цинка являются нестабильными, так как имеют низкие барьеры миграции и должны исчезать при низкотемпературном отжиге. В работе [31] методом позитронной аннигиляционной спектроскопии и исследованиями спектров поглощения образцов $\mathrm{ZnO}$ после отжига в различных средах показано, что наличие межузельных атомов цинка мало вероятно. Также показано, что, так как водород является очень сложным для удаления из среды при росте или отжиге пленок, он присутствует в пленках оксида цинка и действует как мелкий донор, образуя комплексы с вакансиями кислорода. В работе [32] предположено, что термическая стабильность $n$-типа проводимости в $\mathrm{ZnO}$ и ее зависимость от парциального давления кислорода обусловлены наличием в пленках водорода, который кроме межузельного положения может занимать положение кислорода в решетке и образовывать многоцентровые связи с цинком. Про роль водорода в качестве мелкого донора говорится в работах [25,30,33-35].
Энергия образования дефектов зависит от типа проводимости. Полученные образцы имели $n$-тип проводимости. В $\mathrm{ZnO} n$-типа самую низкую энергию образования среди точечных дефектов имеют вакансии цинка $V_{\mathrm{Zn}}$. [36,37]. Собственные дефекты вакансии цинка $V_{\mathrm{Zn}}$ и межузельный кислород $\mathrm{O}_{i}$ относятся к дефектам акцепторного типа [38]. Об энергии образования вакансий кислорода в литературе существуют весьма противоречивые сведения. Согласно [39], энергия образования вакансий кислорода $V_{\mathrm{O}}$ в таких материалах $(\mathrm{ZnO} n$-типа) довольно высока $(3.72$ эВ) даже в сильно нестехиометрических оксидах с избытком атомов $\mathrm{Zn}$. Однако, согласно [25], вакансии кислорода имеют более низкую энергию образования, чем межузельные атомы цинка. В работе [40] показано, что по сравнению с ионизацией вакансии кислорода более легко протекает ионизация межузельного цинка.

В наших пленках присутствует азот, который, с одной стороны, может выступать в качестве анионного заместителя [41], а с другой - возможно образование комплексов донорного типа $\left(\mathrm{N}_{2}\right) \mathrm{O}$ [42]. Согласно [43], азот является акцепторной примесью благодаря атомному размеру и электронной структуре. Атом азота является наиболее близким по размеру к атому кислорода, и, следовательно, он, как ожидается, приведет к минимальной деформации в $\mathrm{ZnO}$. В работе [44] предположили, что, вероятно, только азот может создать мелкий акцепторный уровень в оксиде цинка, а в работах [4553] выдвинута версия, что азот заменяет в оксиде цинка кислород. Однако в работах $[47,54]$ показано, что азот создает в оксиде цинка глубокие акцепторные уровни. Теоретические исследования компенсации азота внутренними дефектами представлены в работе [55]. На основе расчетов они пришли к выводу, что низкий уровень легирования азотом будет наблюдаться в случае использования в качестве источника азота газа $\mathrm{N}_{2}$. Это обусловлено тем, что акцепторы N будут компенсироваться в основном вакансиями кислорода. При высоких уровнях легирования $\mathrm{N}$-акцепторы будут скомпенсированы образованием дефектных комплексов с антисайтами цинка. Согласно [43], остаются спорными выводы о проводимости и механизмах легирования оксида цинка азотом. Следует также отметить, что получение оксида цинка $p$-типа проводимости является очень сложной задачей, так как, с одной стороны, в данном материале преобладает проводимость $n$-типа [2,25,56-58], а с другой - основные дефекты оксида цинка, отвечающие за $n$-тип, компенсируют дефекты $p$-типа [32,59-61].

Также следует отметить работы [62-64], в которых сообщается о том, что наблюдать $p$-тип проводимости в оксиде цинка может мешать поверхностный заряд.

Можем предположить, что хотя использование ионнолучевой обработки приводит к незначительному увеличению концентрации атомов азота от 1.95 до 3.38 ат\%, в пленках оксида цинка, существенного влияния его на свойства в данном исследовании по ряду причин не обнаружено. 
Значение стехиометрического индекса полученных пленок $\mathrm{ZnO}$ меньше единицы, это коррелирует с литературными данными. В [5] установлено, что при распылении $\mathrm{ZnO}$-мишени стехиометрического состава в нанесенных пленках наблюдается недостаток кислорода. Даже при распылении мишени в среде чистого кислорода стехиометрический индекс нанесенных пленок не превышал 0.98. Отклонение оксида цинка от стехиометрии в сторону избытка катионов (либо недостатка анионов) может объясняться значительно большей энергией образования вакансий цинка по сравнению с той же энергией у кислорода [25]. Хотя, как было отмечено выше, следует отметить, что имеются расчеты, показывающие, что вакансии кислорода требуют высоких энергий образования [59]. Результаты проведенного элементного анализа дают возможность предположить, что возможными собственными дефектами в полученных пленках являются вакансии кислорода $V_{\mathrm{O}}$, межузельный цинк $\mathrm{Zn}_{i}$, антисайт $\mathrm{Zn}_{\mathrm{O}}$. Однако изменение удельного сопротивления в зависимости от тока ионной обработки свидетельствует о том, что данные дефекты не могут быть ответственными за электропроводность $n$-типа оксида цинка. Согласно [59-61], $V_{\mathrm{O}}$ (глубокие доноры) не объясняют $n$-тип проводимости. Также полученные результаты коррелируют с подведенным итогом работы [43], где говорится о том, что собственные дефекты $V_{\mathrm{O}}$ могут компенсировать примеси, вводимые для создания $p$-типа. $\mathrm{Zn}_{\mathrm{O}}$ и $\mathrm{Zn}_{i}$ являются неглубокими донорами, но для $\mathrm{Zn}_{\mathrm{O}} n$-типа имеют высокие энергии образования. $\mathrm{Zn}_{\mathrm{O}}$ являются рассеивающими центрами и вряд ли будут стабильны в виде изолированных точечных дефектов. $\mathrm{Zn}_{i}$ имеют довольно низкий миграционный барьер (0.57 эВ), быстро диффундируют к поверхности и отвечают за быстрое восстановление электрических свойств в облученном $\mathrm{ZnO}$.

Изменения стехиометрического индекса и коэффициента упаковки (коэффициента заполнения) в результате введения ионно-лучевой обработки могут свидетельствовать о том, что кислородные вакансии в нашем случае не являются ответственными за изменение удельного сопротивления пленок оксида цинка. В работе [23] говорится, что снижение сопротивления в отожженных пленках легированного оксида цинка связано как с увеличением числа свободных носителей за счет роста концентрации кислородных вакансий, так и с увеличением подвижности носителей вследствие уменьшения их рассеяния на границах зерен. Вероятно, происходит увеличение подвижности носителей вследствие уменьшения их рассеяния на границах зерен, что соответствует изменениям доли кристаллитов оксида цинка с преимущественной ориентацией оси с перпендикулярно поверхности пленок. В работах [65-67] для $\mathrm{ZnO}, \mathrm{SnO}_{2}$ и ITO пленок показано, что на электрофизические свойства пленок оказывают значительное влияние характеристики кристаллической структуры (размер зерна, напряжения, дефекты). Согласно [68], понизить удельное сопротивление пленок оксида цинка можно увеличением температуры подложки или увеличением тока в катушке магнетрона. В указанной работе методом магнетронного распыления керамической мишени получены прозрачные проводящие пленки легированного галлием оксида цинка при температуре подложки $150^{\circ} \mathrm{C}$. Показано, что использование внешней электромагнитной катушки, создающей несбалансированную конфигурацию магнитного поля, позволяет улучшить электрические и структурные свойства оксидных пленок, получаемых на оси системы. Это улучшение связано с бомбардировкой растущей пленки ионами низкой $(\sim 20$ эВ $)$ энергии, увеличивающей подвижность адатомов на ее поверхности и стимулирующей процесс внедрения адатомов в структуру растущей пленки. Бомбардировка растущей пленки приводит к увеличению размеров зерен, что сопровождается увеличением холловской подвижности носителей заряда за счет уменьшения их рассеяния на границах зерен. Рост структурного совершенства приводит к снижению потенциальных барьеров на границах зерен и увеличению подвижности носителей заряда в пленках [21].

Авторы [23] показали, что отжиг в среде с низким содержанием кислорода вызывает сдвиг области края фундаментального поглощения в коротковолновую сторону. В нашем случае ионно-лучевая обработка тоже вызывает сдвиг края поглощения в коротковолновую область.

Изменение величины ширины запрещенной зоны может быть связано с различными причинами. В работах [69-72] установлено, что ширина запрещенной зоны растет с уменьшением размера частиц. В [47] замечено, что увеличение уровня легирования вызвало увеличение оптической ширины запрещенной зоны пленок, что может быть объяснено проявлением эффекта Бурштейна-Мосса.

Увеличение запрещенной зоны было замечено ранее в нестехиометрических пленках $\mathrm{ZnO}$ [73]. Следует отметить работу [6], в которой установлено, что оптическая ширина запрещенной зоны тонких пленок модифицированного оксида цинка (синтезируемого в условиях бомбардировки компонентами низкотемпературной плазмы) меняется от 3.26 до 3.32 эВ в зависимости от давления в распылительной камере, которое авторы опосредованно связывали с энергией ионной бомбардировки. В данной работе показано, что межплоскостное расстояние, показатель преломления и оптическая ширина запрещенной зоны обнаруживают хорошую корреляцию с динамикой изменения энергии бомбардировки. Наблюдается практически прямая связь между показателем преломления и шириной запрещенной зоны. В нашем случае также наблюдается прямая взаимосвязь между показателем преломления и шириной запрещенной зоны.

\section{5. Заключение}

Ионно-лучевая обработка, чередующаяся с процессом магнетронного напыления тонких пленок оксида цинка, вызывает уменьшение скорости роста; сдвиг края 
поглощения в коротковолновую область и увеличение ширины запрещенной зоны и показателя преломления; увеличение стехиометрического индекса и захват примесей ( $\mathrm{N}, \mathrm{Ne}$ и $\mathrm{Ar}$ ); уменьшение удельного сопротивления; уменьшение размеров ОКР; но не влияет на прозрачность получаемых пленок в области слабого поглощения.

По результатам элементного анализа можно предположить, что возможными собственными дефектами в полученных пленках являются вакансии кислорода $V_{\mathrm{O}}$, межузельный цинк $\mathrm{Zn}_{i}$, антисайт $\mathrm{Zn}_{\mathrm{O}}$. Сопоставление результатов изменения удельного сопротивления и изменение стехиометрического индекса и коэффициента упаковки (коэффициента заполнения) с литературными данными об энергиях образования дефектов свидетельствуют о том, что кислородные вакансии в данном случае не являются ответственными за изменение удельного сопротивления пленок оксида цинка. Более вероятная причина увеличения электропроводности исследуемых пленок связана с увеличением подвижности носителей вследствие уменьшения их рассеяния на границах зерен, что соответствует изменениям доли кристаллитов оксида цинка с преимущественной ориентацией оси $c$ перпендикулярно поверхности пленок. Увеличение оптической ширины запрещенной зоны, которое может быть объяснено проявлением эффекта Бурштейна-Мосса, может быть связано с неконтролируемым захватом примесей водорода.

\section{Конфликт интересов}

Авторы заявляют что у них нет конфликта интересов.

\section{Список литературы}

[1] C.F. Klingshirn, A. Waag, A. Hoffmann, J. Geurts. Zinc Oxide: From Fundamental Properties Towards Novel Applications (Springer, 2010).

[2] C. Jagadish, S.J. Pearton. Zinc Oxide Bulk, Thin Films and Nanostructures: Processing, Properties, and Applications (Elsevier, 2006).

[3] K. Ellmer, A. Klein, B. Rech. Transparent conductive zinc oxide: Basics and applications in thin film solar cells (Springer Verlag: Berlin, Germany, 2008).

[4] H. Kim, N.L. Hung, E. Ahn, H. Jung, D. Kim. J. Korean Phys. Soc., 57 (6), 1784 (2010).

[5] А.П. Достанко, О.А. Агеев, Д.А. Голосов, С.М. Завадский, Е.Г. Замбург, Д.Е. Вакулов, З.Е. Вакулов. ФТП, 48 (9), 1274 (2014).

[6] А.А. Сердобинцев, А.Г. Веселов, О.А. Кирясова. ФТП, 42 (4), 496 (2008).

[7] С.В. Работкин. Автореф. канд. дис. (Томск, 2009).

[8] В.М. Ветошкин, Р.М. Закирова, П.Н. Крылов, И.А. Суворов. ВТT, 21 (1), 57 (2011).

[9] В.М. Ветошкин, Р.М. Закирова, Н.В. Костенков, П.Н. Крылов. Поверхность. Рентгеновские, синхротронные и нейтронные исследования, 2, 17 (2012).

[10] П.Н. Крылов, Р.М. Закирова, И.В. Федотова, Ф.З. Гильмутдинов. ФТП, 47 (6), 859 (2013).
[11] П.Н. Крылов, Р.М. Закирова, И.В. Федотова. ФТП, 48 (9), 1269 (2014).

[12] В.М. Ветошкин, П.Н. Крылов, И.В. Федотова, Р.М. Закирова. В сб.: Tp. ХХIV Межсдунар. конф. „Радиационная физика твердого тела“ (М., Изд-во ФГБНУ „НИИ ПМТ“, 2014).

[13] П.Н. Крылов, Р.М. Закирова, И.В. Федотова. ФТП, 48 (6), 763 (2014).

[14] П.Н. Крылов, Р.М. Закирова, И.В. Федотова, Р.Г. Акашкина, Е.П. Широбоков. Хим. физика и мезоскопия, 16 (2), 235 (2014).

[15] С.С. Алалыкин, П.Н. Крылов. ПТЭ, 2, 149 (2005).

[16] Я.С. Уманский, Ю.А. Скаков, А.Н. Иванов, Л.Н. Расторгуев. Кристаллография, рентгенография и электронная микроскопия (М., Металлургия, 1982) с. 632.

[17] В.В. Брус, Э.Д. Ковалюк, П.Д. Марьянчук. ЖТФ, 82 (8), $110(2012)$

[18] С.И. Садовников, Н.С. Кожевникова, А.А. Ремпель. ФТП, 44 (10), 1394 (2010).

[19] Физика тонких пленок, под общей ред. Г. Хасса, М. Франкомба, Р. Гофмана (М., Мир, 1978) т. VIII, с. 320.

[20] А.Ф. Белянин, В.А. Кривченко, Д.В. Лопаев, Л.В. Павлушкин, П.В. Пащенко, В.Г. Пирогов, С.Н. Поляков, Н.В. Суетин, Н.И. Сушенцов. Технология и конструирование в электронной аппаратуре, 6, 48 (2006).

[21] А.Х. Абдуев, А.К. Ахмедов, А.Ш. Асваров. Письма ЖТФ, 40 (14), 71 (2014).

[22] О.А. Александрова, А.И. Максимов, В.А. Мошников, Д.Б. Чеснокова. / (СПб., Технолит, 2008) с. 240.

[23] А.И. Бажин, А.Е. Покинтелица, Н.С. Щеглова, В.А. Ступак, А.Н. Троцан. Вісник Донбаської національної академії будівництва і архітектури, 4, 109 (2013).

[24] P. Erhart, K. Albe, A. Klein. Phys. Rev. B, 73 (20), 205203 (2006).

[25] F. Oba, A. Togo, I. Tanaka, J. Paier, G. Kresse. Phys. Rev. B, 77 (24), 245202 (2008).

[26] F. Oba, S.R. Nishitani, S. Isotani, H. Adachi, I. Tanaka. J. Appl. Phys., 90 (11), 824 (2001).

[27] S. Limpijumnong, C.G. Van de Walle. Phys. Rev. B, 69 (13), 035207 (2004).

[28] V. Bhosle, A. Tiwari, J. Narayan. Appl. Phys. Lett., 88, 032106 (2006).

[29] A.F. Kohan, G. Ceder, D. Morgan, C.G. Van de Walle. Phys. Rev. B, 61 (22), 15019 (2000).

[30] F.A. Selim, M.H. Weber, D. Solodovnikov, K.G. Lynn. Phys. Rev. Lett., 99 (8), 085502 (2007).

[31] A. Janotti, C.G. Van de Walle. Nature Materials, 6 (1), 44 (2007).

[32] F. Tuomisto, V. Ranki, K. Saarinen, D.C. Look. Phys. Rev. Lett., 91 (5), 205502 (2003).

[33] F. Tuomisto, K. Saarinen, D.C. Look, G.C. Farlow. Phys. Rev. B, 72 (18), 085206 (2005).

[34] A. Janotti, G. Chris. Phys. Rev. B, 76 (18), 165202 (2007).

[35] C.H. Park, S. Zhang, S.-H. Wei. Phys. Rev. B, 66 (7), 073202 (2002).

[36] Y. Yan, S.B. Zhang, S.T. Pantelides. Phys. Rev. Lett., 86 (25), 5723 (2001).

[37] A. Janotti, C.G. Van de Walle. US Rep. Prog. Phys., 72, 126501 (2009)

[38] Ü. Özgür, Ya.I. Alivov, C. Liu, A. Teke, M. Reshchikov, S. Dogan, V. Avrutin, S.-J. Cho, H. Morkoç. J. Appl. Phys., 98 (4), 041301 (2005). 
[39] Z-C. Jin, I. Hamberg, C.G. Granqvist. J. Appl. Phys., 64, 5117 (1988).

[40] B. Stjerna, C.G. Granqvist. Thin Sol. Films, 193/194, 704 (1990).

[41] K. Tominaga, T. Ueda, T. Ao, M. Kataoka, I. Mori. Thin Sol. Films, 281/282, 194 (1996).

[42] А.Н. Захаров, К.В. Оскомов, С.В. Работкин, А.А. Соловьев, Н.С. Сочугов. ЖТФ, 80 (5), 127 (2010).

[43] P. Pushparajaht, A. Kariem Aroft, S. Radhakrishnat. Phys. D: Appl. Phys., 4 (3), 1518 (1994).

[44] Y. Zhang, B. Lin, X. Sun, Z. Fu. Appl. Phys. Lett., 86 (13), 131910 (2005).

[45] J.W. Orton. Phil. Mag., 49 (1), L1 (1984).

[46] E.E. Kawaja, M.A. Al-Daous, S.M.A. Durani, M.F. Al-Kuhaili. Thin Sol. Films, 485 (3), 16 (2005).

[47] Ю.П. Лепескин, Р.С. Зырянов. В сб.: Итоги науки в теории и практике. 2016. ХХІІ Международной научной конференции (М., Евразийское научное общество, 2016) вып. 10, с. 91.

[48] A.P. Roth, B.W. James, D.F. Williams. Phys. Rev. B, 25 (12), 7836 (1982).

[49] Z.-Q. Fang, B. Claflin, D.C. Look, L. Lei Kerr, X. Li. J. Appl. Phys., 102, 023714 (2007).

[50] K. Thonke, Th. Gruber, N. Teofilov, R. Schöfelder, N. Kerwien, A. Waag, R. Sauer. Physica B, 308, 945 (2001).

[51] X.-L. Guo, J.-H. Choi, H. Tabata, T. Kawai. Jpn. J. Appl. Phys., 40, L177 (2001).

[52] B.K. Meyer, H. Alves, D.M. Hofmann, W. Kriegseis, D. Forster, F. Bertram, J. Christen, A. Hoffmann, M. Straßburg, M. Dworzak, U. Haboeck, A.V. Rodina. Phys. Status Solidi B, 241, 231 (2004).

[53] S. Lautenschlaeger, S. Eisermann, B.K. Meyer, G. Callison, M.R. Wagner, A. Hoffmann. Phys. Status Solidi RRL, 3, 16 (2009).

[54] X.-L. Guo, J.-H. Choi, H. Tabata, T. Kawai. Jpn. J. Appl. Phys. Pt. II, 40, L177 (2001).

[55] E.-C. Lee, Y.-S. Kim, Y.-G. Jin, K.J. Chang. Phys. Rev. B, 64, 085120 (2001).

[56] D.C. Look. Mater. Sci. Eng. B, 80, 383 (2001).

[57] S.B. Ogale. Thin Films and Heterostructures for Oxide Electronics (N.Y., Springer, 2005).

[58] N.H. Nickel, E. Terukov. Zinc Oxide - A Material for Microand Optoelectronic Applications (Netherlands, Springer, 2005).

[59] A. Janotti, C.G. Van de Walle. Appl. Phys. Lett., 87, 122102 (2005).

[60] A. Janotti, C.G. Van de Walle. J. Cryst. Growth, 287, 58 (2006).

[61] A. Janotti, C.G. Van de Walle. Phys. Rev. B, 75, 165202 (2007).

[62] O. Schmidt, P. Kiesel, C.G. Van de Walle, N.M. Johnson, J. Nause, G.H. Dö hler. Jpn. J. Appl. Phys. Pt. 1, 44, 7271 (2005).

[63] O. Schmidt, A. Geis, P. Kiesel, C.G. Van de Walle, N.M. Johnson, A. Bakin, A. Waag, G.H. Döhler. Superlatt. Microstruct., 39, 8 (2006).

[64] D.C. Look. Surf. Sci., 601, 5315 (2007).

[65] Z-C. Jin, I. Hamberg, C.G. Granqvist. J. Appl. Phys., 64, 5117 (1988).

[66] B. Stjerna, C.G. Granqvist. Thin Sol. Films, 193/194, 704 (1990).
[67] K. Tominaga, T. Ueda, T. Ao, M. Kataoka, I. Mori. Thin Sol. Films, 281/282, 194 (1996).

[68] А.Н. Захаров, К.В. Оскомов, С.В. Работкин, А.А. Соловьев, Н.С. Сочугов. ЖТФ, 80 (5),127 (2010).

[69] P. Pushparajaht, A. Kariem Aroft, S. Radhakrishnat. Phys. D: Appl. Phys., 4 (3), 1518 (1994).

[70] Y. Zhang, B. Lin, X. Sun, Z. Fu. Appl. Phys. Lett., 86 (13), 131910 (2005).

[71] J.W. Orton. Phil. Mag., 49 (1), L1 (1984).

[72] E.E. Kawaja, M.A. Al-Daous, S.M.A. Durani, M.F. Al-Kuhaili. Thin Sol. Films, 485 (3), 16 (2005).

[73] A.P. Roth, B.W. James, D.F. Williams. Phys. Rev. B, 25 (12), 7836 (1982).

Редактор Г.А. Оганесян

\section{Effect of ion-beam processing in the process of RF magnetron sputtering on the properties of $\mathrm{ZnO}$ films}

\section{P.N. Krylov, A.S. Alalykin, E.A. Durman, R.M. Zakirova, I.V. Fedotova}

Udmurt State University,

426034 Izhevsk, Russia

Abstract The effect of ion-beam treatment, alternating with the magnetron sputtering process, on the properties zinc oxide of thin films is considered. Ion-beam treatment causes a decrease in the growth rate, the size of the coherent scattering regions and resistivity. The stoichiometric index, the band gap and the refractive index increase. The transparency of the films in the area of weak absorption does not change. 